\title{
STUDI AWAL RANCANGAN BIDIRECTIONAL-MULTIUSER PADA VISIBLE LIGHT COMMUNICATION UNTUK APLIKASI DALAM RUANG (INDOOR)
}

\author{
Syifaul Fuada \\ Microelectronic Center \\ fsyifaul@gmail.com
}

\begin{abstract}
ABSTRAK
Visible Light Communication (VLC) atau komunikasi cahaya tampak merupakan teknologi yang sedang on fire selama beberapa tahun ini dan diasumsikan akan terus berlanjut beberapa dekade ke depan karena banyak kelebihan yang ditawarkan, yakni telah tersedia infrastruktur utama berupa lampu penerangan sehingga bersifat cost-effective, bebas lisensi, lebih aman (secure), kecepatan transmisi mencapai GHz, dan tidak memiliki interferensi elektromagnetik. Karena VLC adalah teknologi yang relatif baru, maka standar komunikasinya juga cenderung berkembang ialah standar IEEE 802.15.17 yang terpublikasi akhir tahun 2010 lalu. Standar ini masih mengajukan teknik modulasi dan juga komunikasi pada skenario point-to-point namun sampai saat ini belum mengakomodasi sistem komunikasi dengan skenario Multiuser sekaligus transmisi Bi-directional. Makalah ini merupakan proposal rancangan dalam rangka mendesain sistem VLC secara bi-directional (uplink dan downlink) yang mampu dipakai pada skema multiuser dengan kecepatan bitrate pada downlink mencapai 1 Mbps untuk aplikasi dalam ruang (indoor). Makalah ini terbagi menjadi beberapa bagian pembahasan. Pertama mendefinisikan latar belakang akan dilakukannya sebuah penelitian untuk memperbaiki platform penelitian yang terdahulu dan kontribusinya. Bagian kedua memaparkan penelitian yang relevan beserta state of the art antara penelitian ini dengan lainnya. Bagian ketiga merinci teori dasar. Bagian keempat memaparkan metodologi penelitian dan terakhir adalah batasan masalah dan penutup.
\end{abstract}

Kata kunci: Bidirectional, Multiuser, Visible Light Communication, Aplikasi Indoor

\begin{abstract}
Visible Light Communication (VLC) is a technology that has been "on fire" for several years and it is assumed to continue in the next few decades because of many advantages offered, namely the main infrastructure provided in the lighting form so it is cost-effective, free license, safer (secure), the transmission speed reaches GHz, and has no electromagnetic interference. Since VLC is a relatively new technology, then its communication standards that is also tend to develop is IEEE 802.15.17 standard published in late 2010. This standard still proposes modulation techniques as well as communications in the point-to-point scenario but until now has not accommodated the communication system with Multiuser scenario as well as Bi-directional transmission. This paper is a proposal to design a bi-directional (uplink and downlink) VLC system that can be used on multiuser schemes with bitrate speeds of downlink up to $1 \mathrm{Mbps}$ for indoor applications. This paper is divided into several parts of the discussion. First define the research background to improve the previous research platform and its contribution. The second part describes the relevant research along with the state of the art among this study and others. The third section details the basic theories. The fourth section describes the methodology of research and the last section is the limitation of the problem and the conclusion.
\end{abstract}

Keywords: Bidirectional, Multiuser, Visible Light Communication, Indoor Applications

DOI: $10.15408 /$ jti.v10i1.6813 


\section{PENDAHULUAN}

\subsection{Latar Belakang}

Visible Light Communication (VLC) atau juga dikenal dengan Li-Fi adalah salah satu alternatif komunikasi nirkabel selain radio. VLC menggunakan cahaya tampak dengan panjang gelombang 375 hingga $780 \mathrm{~nm}$ sebagai medium komunikasi [1]. Sistem VLC mempunyai beberapa keunggulan yang ditawarkan dibandingkan komunikasi Radio Frequency (RF) dan Infra Red (IR), yakni cost-effective, bebas lisensi, lebih aman (secure), highest speed, dan tidak memiliki interferensi elektromagnetik [2]. Pada tahun 2014, proyek Ultra-Parallel Visible Light Communication (UP-VLC) berhasil mencapai kecepatan transmisi data hingga 3 Gbps menggunakan dengan jarak antara transmitter dan receiver dalam percobaan tersebut hanya beberapa sentimeter [3]. Namun hasil penelitian ini menunjukkan potensi teknologi VLC sebagai teknologi alternatif yang menarik untuk menyediakan akses kecepatan tinggi bagi perangkat seperti tablet, laptop, smartphone dan perangkat-perangkat lain dalam ruang (indoor environment).

Komunikasi cahaya tampak dapat dilakukan dengan menggunakan $L E D$ sebagai transmitter dan Photo Detector (PD) sebagai receiver. Transmitter mengkonversi sinyal listrik menjadi sinyal optik dan sebaliknya receiver/detector mengkonversi daya optik menjadi arus listrik. Transmisi data dapat dilakukan dengan mengubah-ubah level iluminasi LED pada sisi transmitter (Intensity Modulation). Lalu photodioda pada sisi receiver membangkitkan pulsa listrik yang linier terhadap level iluminasi yang diterima (Direct Detection) [4].

Standar untuk sistem VLC baru dirancang dalam 5 tahun belakangan ini, yakni dimulai dari tahun 2009 dimana IEEE 802.15.17 membentuk task group yang bekerja untuk membuat standar VLC yang meliputi physical layer dan medium access control (MAC) berdasarkan pendekatan clean slate. Selanjutnya draft standar IEEE 802.15.7 tersebut dipublikasikan pada Tahun 2010. Draft standar ini mengajukan penggunaan beberapa teknik modulasi antara lain On-Off Keying (OOK), Variable Pulse-Position Modulation (VPPM), dan Color-Shift Keying (CSK). Selanjutnya, standard IEEE 802.15.7 tersebut juga mengajukan komunikasi VLC dengan skenario point-to-point. Namun sampai saat ini belum mengakomodasi sistem komunikasi dengan skenario Multiuser sekaligus transmisi dua arah atau Bi-directional secara uplink maupun downlink.

Belum adanya standar baku tersebut membuat para peneliti dari seluruh dunia mengajukan berbagai metode dalam satu dekade terakhir ini. Seperti yang dilakukan oleh [5] dan [6] yang mengusulkan metode modulasi CSK untuk skema Multiuser. Namun penelitian ini berfokus pada sisi downlink sehingga diperlukan pengembangan lebih lanjut agar dapat digunakan untuk transmisi uplink. Penelitian lain dilakukan oleh [7] dengan skema Bi-directional Multiuser menggunakan metode user allocation. Namun pada penelitian ini, penggunaan media cahaya adalah LED warna putih baik pada bagian receiver ataupun transmitter, sehingga algoritma yang ditanam pada sistem sangat kompleks.

Pada penelitian yang akan dilakukan, penulis mengusulkan sistem VLC secara bidirectional dengan LED tiga warna pada bagian transmitter sebagai user untuk membedakan berbagai user dalam satu ruangan tersebut, yakni led merah, led biru dan led hijau. Pada bagian transmitter, penulis menggunakan LED warna putih. Adapun artikel ini merupakan hasil orisinil dari penelitian yang telah penulis lakukan.

Batasan masalah dalam penelitian ini adalah sebagai berikut:

- Physical layer dari VLC dirancang adalah untuk aplikasi dalam ruangan (indoor environment)

- Penelitian VLC berfokus pada skema Bidirectional yakni komunikasi dilakukan dua arah baik secara downlink ataupun uplink.

- Pada skema multiuser penulis menggunakan multicolour-LED dengan batasan tiga warna, yakni red warna merah, LED warna biru dan led warna hijau.

- Ruangan unjuk kerja sistem VLC dibatasi dengan ukuran $p \times l \times t=3 \mathrm{~m} \times 3 \mathrm{~m} \times 3 \mathrm{~m}$.

- Kecepatan data (bitrate) pada downlink maksimal adalah $\sim 1 \mathrm{Mbps}$

- Modulasi yang digunakan adalah PWM.

\subsection{Kontribusi Penelitian dan Tujuan}

Melalui skema penelitian ini diharapkan hasil demonstrasi/ unjuk kerja sistem dapat memperbaiki performa dari penelitian-penelitian sebelumnya (penelitian yang dilakukan oleh [5], [6], [7]). Harapannya produk luaran penelitian dapat diterapkan sebagai platform komunikasi yang ideal pada skala dalam ruang (indoor) baik 
perkantoran, instansi, rumah hunian atau bangunan lainnya di masa mendatang. Lebih jauh lagi, dapat dijadikan referensi dan tolok ukur dalam pengembangan berbagai penelitian yang lebih lanjut baik dari penulis sendiri ataupun peneliti mancanegara sehingga pada akhirnya menjadi standar platform IEEE 802.15.7 untuk skema Bi-directional sekaligus Multiuser pada sisi physical layer. Tujuan dari penulisan makalah ini adalah untuk mendesain sistem VLC secara bi-directional (uplink dan downlink) yang mampu dipakai pada skema multiuser dengan kecepatan bitrate pada downlink mencapai $1 \mathrm{Mbps}$.

\subsection{Penelitian yang Relevan}

Untuk mengetahui hasil penelitian terkini sekaligus sebagai perbandingan antara penelitian yang sudah pernah dilakukan dengan penelitian ini diperlukan studi literatur. Literatur yang direviu adalah artikel-artikel berhubungan dengan Bi-directional sekaligus Multiuser pada VLC. Detail ditunjukkan pada Tabel 1, setidaknya terdapat tiga belas hasil riset yang dijadikan sebagai komparasi.

Tabel 1. Hasil riset penelitian VLC: State of The Art

\begin{tabular}{|c|c|c|c|c|c|c|c|c|c|c|}
\hline No & Researcher & Keterangan & $\begin{array}{c}\text { Bi- } \\
\text { direc } \\
t\end{array}$ & $\begin{array}{c}\text { Multi } \\
\text { user }\end{array}$ & $\begin{array}{l}\text { Skema } \\
\text { Ruang } \\
\quad(\mathrm{m})\end{array}$ & $\begin{array}{c}\text { Modulas } \\
\text { i }\end{array}$ & Trans. & Rec. & $\begin{array}{c}\text { Up } \\
\text { link }\end{array}$ & $\begin{array}{c}\text { Down } \\
\text { link }\end{array}$ \\
\hline 1 & $\begin{array}{l}\text { S.V Tiwari et al. } \\
(2015)\end{array}$ & $\begin{array}{l}\text { Metode Color Coded } \\
\text { Multiple Acces } \\
\text { (CCMA) }\end{array}$ & ya & ya & $5 \times 5 \times 3$ & $\begin{array}{l}\text { OOK- } \\
\text { OFDM }\end{array}$ & $\begin{array}{l}\text { P-LED \& } \\
\text { RGB LED }\end{array}$ & PD & $\begin{array}{r}31.2 \\
\mathrm{Mb} / \mathrm{s}\end{array}$ & $\begin{array}{l}62,5 \\
\mathrm{Mb} / \mathrm{s}\end{array}$ \\
\hline 2 & $\begin{array}{l}\text { S.H. Yang et al. } \\
(2011)\end{array}$ & $\begin{array}{l}\text { Metode Wavelength } \\
\text { Filtering }\end{array}$ & tidak & ya & $5 \times 5 \times 3$ & - & $\begin{array}{l}\text { LED R, } \\
\text { G, B }\end{array}$ & PD & - & $\begin{array}{c}300 \\
\mathrm{Mb} / \mathrm{s}\end{array}$ \\
\hline 3 & B. Li et al. (2015) & Metode Optical strategy & tidak & ya & $\begin{array}{c}7,5 \times 7,5 \times \\
3\end{array}$ & 2PAM & LED & $\mathrm{PD}$ & - & $\begin{array}{c}100 \\
\mathrm{Mb} / \mathrm{s}\end{array}$ \\
\hline 4 & $\begin{array}{l}\text { H. Ma et al. } \\
(2015)\end{array}$ & $\begin{array}{l}\text { Coordinated } \\
\text { Broadcasting model }\end{array}$ & tidak & ya & $5 \times 5 \times 3$ & OOK & LED & PD & - & - \\
\hline 6 & $\begin{array}{l}\text { S.H Chen et al. } \\
(2014)[21]\end{array}$ & $\begin{array}{l}\text { Color Filter using } \\
\text { Camera + SIFT } \\
\text { Algoritm (skema } \\
\text { outdoor) }\end{array}$ & ya & $\begin{array}{c}\text { Tida } \\
\mathrm{k}\end{array}$ & - & $\mathrm{OOK}$ & RGB LED & $\begin{array}{l}\text { Camer } \\
\text { a } \\
\text { sensor }\end{array}$ & - & $540 \mathrm{~b} / \mathrm{s}$ \\
\hline 7 & $\begin{array}{l}\text { C. Gossu et al. } \\
{[22]}\end{array}$ & $\begin{array}{l}\text { Komunikasi point to } \\
\text { point }\end{array}$ & $\begin{array}{c}\text { Tida } \\
\mathrm{k}\end{array}$ & tidak & $\begin{array}{l}\text { Jarak } \\
2,5 \mathrm{~m}\end{array}$ & OFDM & RGB LED & APD & & $\begin{array}{c}780 \\
\mathrm{Mb} / \mathrm{s}\end{array}$ \\
\hline 8 & $\begin{array}{l}\text { W. Yuanquan. et } \\
\text { al }\end{array}$ & Frequency determining & ya & tidak & - & $\begin{array}{l}\text { QAM- } \\
\text { OFDM }\end{array}$ & RGB LED & $\mathrm{PD}$ & $\begin{array}{l}1.15 \\
\mathrm{~Gb} / \mathrm{s}\end{array}$ & $\begin{array}{c}300 \\
\mathrm{Mb} / \mathrm{s}\end{array}$ \\
\hline 9 & $\begin{array}{l}\text { J.M.L. Rivera et } \\
\text { al }\end{array}$ & $\begin{array}{l}\text { Math model for skema } \\
\text { multiuser }\end{array}$ & tidak & $\mathrm{Ya}$ & - & - & RGB LED & $\mathrm{PD}$ & - & - \\
\hline 10 & $\begin{array}{l}\text { A. Sewaiwar } \\
(2015)\end{array}$ & Optical strategy & tidak & ya & $5 \times 5 \times 3$ & OOK & $\begin{array}{c}\text { LED } \\
\text { R,G,B }\end{array}$ & PD & - & $3 \mathrm{~Gb} / \mathrm{s}$ \\
\hline 11 & Q. Wang & MIMO-OFDM models & tidak & ya & $5 \times 5 \times 3$ & OFDM & $p$-LED & PD & - & - \\
\hline 12 & $\begin{array}{l}\text { Y. Wang et al } \\
{[11]}\end{array}$ & $\begin{array}{l}\text { Asyncronus Bi- } \\
\text { directional }\end{array}$ & ya & tidak & $5 \times 5 \times 3$ & - & RGB & PIN & & $\begin{array}{c}575 \\
\mathrm{Mb} / \mathrm{s}\end{array}$ \\
\hline 13 & C. Tang et al [8] & $\begin{array}{l}\text { Protograph-based low- } \\
\text { density parity-check } \\
\text { (P-LDPC) codes }\end{array}$ & tidak & tidak & & & RGB & PIN & - & - \\
\hline 14 & (penelitian ini) & Color filtering & ya & ya & $5 \times 5 \times 3$ & PWM & $\begin{array}{l}\text { LED R, } \\
\mathrm{G}, \mathrm{B} \& p^{-} \\
\mathrm{LED}\end{array}$ & PD & $\begin{array}{c}1 \\
\mathrm{Mb} / \mathrm{s}\end{array}$ & $1 \mathrm{Mb} / \mathrm{s}$ \\
\hline
\end{tabular}


Tabel 1 terbagi menjadi sebelas kolom, yakni nomor urut berdasarkan tahun, keterangan teknologi yang di improve, keterangan bidirectional atau tidak, keterangan multiuser atau tidak, skema ruangan indoor yang digunakan dalam demonstrasi penelitian, perangkat transmitter, perangkat receiver, kecepatan uplink dan kecepatan downlink yang diperoleh.

S.V. Tiwari [17] mengusulkan skema Bidirectional sekaligus Multiuser dengan rangkaian fully digital. Platform menggunakan LED warna merah, hijau dan biru (RGB) sebagai downlink dan LED fosfor warna putih ( $p$-LED) untuk uplink. Transmisi downlink untuk perangkat data pengguna menggunakan LED warna merah dan perangkat smarthome menggunakan LED warna hijau. Sedangkan transmisi untuk kedua jenis perangkat adalah menggunakan warna biru. Hasil penelitian menunjukkan sistem dapat bekerja sebagaimana mestinya dan mampu untuk meminimalisir flicker-free. Perbedaan penelitian [17] dengan penelitian ini terletak pada jenis modulasi dan desain penelitian. Penulis menggunakan modulasi PWM dan batasan bitrate maksimal 1 $\mathrm{Mb} / \mathrm{s}$.

Selanjutnya S.H. Yang et al. [18] melakukan penelitian yang focus pada komunikasi directional point-to-point atau satu arah dengan optimalisasi multisel menggunakan RGB LED yang disusun secara heksagonal. Tujuannya adalah untuk meminimalisir gangguan (interference) yang disebabkan oleh perbedaan panjang gelombang dari warna-warni cahaya LED RGB saat melakukan uplink. Skenario array LED RGB secara heksagonal ini dapat lebih ditingkatkan performansinya dengan menambahkan filter warna. Sementara penelitian ini berfokus pada Bidirectional Multiuser.

B. Li et al. [19] mengangkat topik sistem komunikasi menggunakan cahaya tampak dengan skenario Multiuser dan Multi Input Multi Output (MIMO). Modulasi yang dipakai adalah 2PAM, LED putih sebagai transmitter dan photodiode sebagai receiver. Meskipun kecepatan Donwlink yang didapatkan adalah 100 $\mathrm{Mb} / \mathrm{s}$, penelitian ini tidak mengakomodasi komunikasi secara Bidirectional.

H. Ma et al. [20] merumuskan teknik bagaimana melakukan koordinasi antara perangkat transmitter dengan satu user. Metode ini dinamakan Coordinated Broadcasting Model untuk skema multiuser. Modulasi yang digunakan adalah OOK, perangkat transmitter menggunakan LED putih dan photodiode pada bagian receiver.

W. Yuanquan. et al [23] membahas secara focus tentang sistem komunikasi bi-directional point-to-point VLC dalam ruang (indoor) berbasis RGB-LED sebagai transmitter dan PD sebagai receiver. Modulasi yang digunakan adalah QAM-OFDM dan metode yang digunakan untuk pengenalan pola warna LED yang dipancarkan adalah berdasarkan perbedaan frekuensi. Untuk downlink digunakan frekuensi rendah sedangkan untuk uplink menggunakan frekuensi tinggi. Bit rate yang diperoleh mencapai $1.15 \mathrm{~Gb} / \mathrm{s}$ untuk downlink dan dan untuk uplink $300 \mathrm{Mb} / \mathrm{s}$. Penelitian ini tidak mengakomodasi skema Multiuser. Selanjutnya J.M.L. Rivera et al [24] merumuskan perhitungan matematis untuk mendapatkan sistem VLC yang dapat beradaptasi dengan berbagai ukuran ruangan untuk dapat diaplikasikan pada skenario point to pointmultiuser. Sementara penelitian ini dipakai untuk skema Bidirectional-Multiuser.

A. Sewaiwar [25] merumuskan metode Double Optical Diversity (DOD) pada skema multiuser menggunakan RGB LED. Didapatkan kecepatan data downlink mencapai 3-Gb/s dengan modulasi OOK. Penelitian ini tidak mengakomodasi komunikasi multiuser. Selanjutnya Q. Wang [26] menyelidiki konfigurasi yang efektif dari komunikasi multiuser-MIMO menggunakan modulasi OFDM dengan menggunakan parameter variasi jarak dari link transmitter-receiver, waktu delay pada multiuser dan perbedaan frekuensi. LED yang digunakan adalah $p$-LED dan PD. Hasil penelitian adalah sejauh pemodelan saja sehingga tidak dicantumkan berapa kecepatan data downlink yang didapatkan.

Untuk mempermudah melihat posisi penelitian ini, maka dapat dibuat taksonomi, pengelompokan ditunjukkan pada Gambar 1 . Secara garis besar dibagi menjadi dua bagian yakni indoor dan outdoor. Khusus pada bagian indoor model komunikasi dibagi menjadi dua bagian yakni Bi-directional (komunikasi dua arah) dan Directional. 


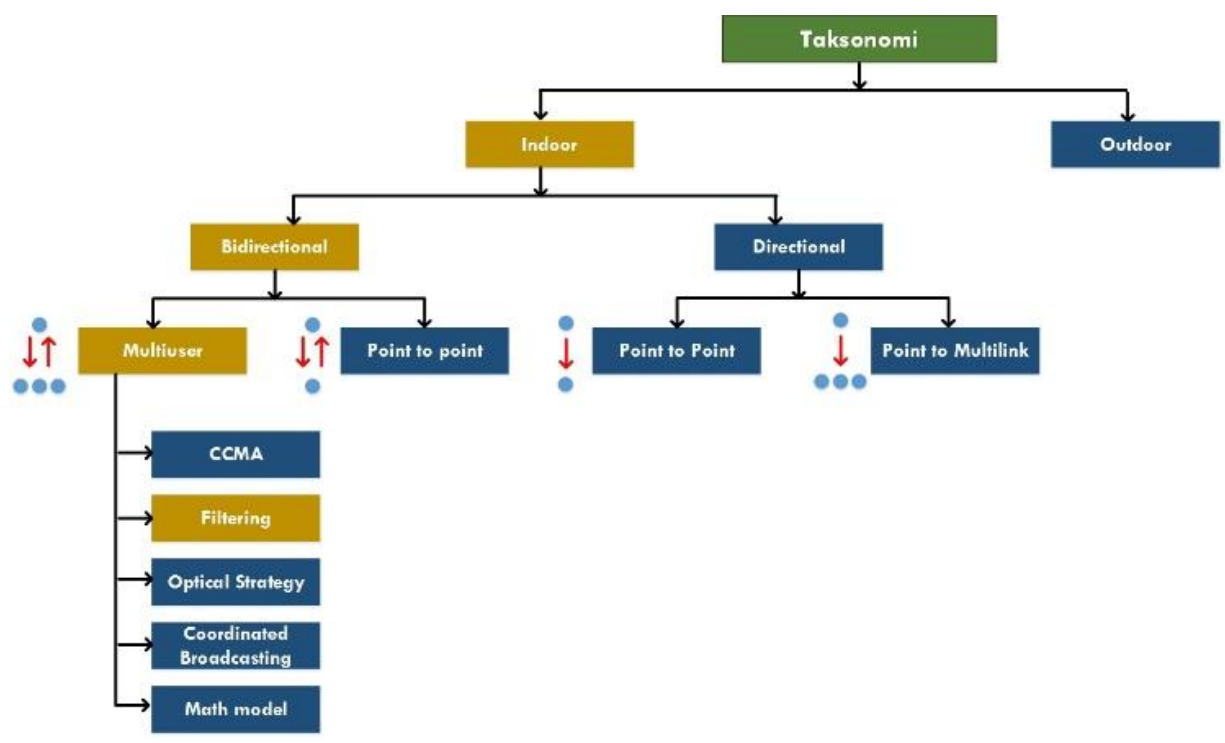

Gambar 1. Taksonomi penelitian skema VLC

Penelitian ini berfokus pada skema multiuser dengan menggunakan metode filtering colour untuk mengenali pola warna LED RGB pada receiver.

\section{LANDASAN TEORI}

\subsection{Perbandingan VLC dengan media lain}

Penggunaan cahaya tampak sebagai media komunikasi dianggap sebagai satu langkah maju untuk menciptakan konsep "Green Communication" [15]. VLC juga menjadi solusi terhadap permasalahan larangan penggunaan radio di tempat-tempat seperti di daerah pertambangan dan kilang minyak, di rumah sakit, di kabin pesawat, dll.

Cahaya tampak menyediakan bandwidth frekuensi sekitar $400 \mathrm{THz}$ yang tak berlisensi dan secure. Perkiraan besar bandwidth adalah 1000 kali lebih lebar dibandingkan kapasitas frekuensi radio yang selama ini digunakan untuk sarana komunikasi [9]. Pada komunikasi Radio Frequency (RF) dan Infra Red (IR) memerlukan base station khusus sehingga memerlukan tambahan suplai energi. Sedangkan pada VLC tidak memerlukan banyak tambahan suplai energy karena memanfaatkan infrastruktur lampu penerangan yang telah tersedia sebagai perangkat komunikasi. Implementasi lebih murah dan mudah [12].

Perbedaan terbesar antara RF dan IR dengan VLC adalah propagasi terhadap penghalang. RF dapat menyediakan koneksi yang dapat menembus suatu penghalang sedangkan koneksi VLC dan IR tidak dapat menembus penghalang, tembok misalnya. Namun justru dengan karakteristik seperti ini, VLC dapat menyediakan koneksi yang lebih aman (secure) dan lebih cepat kepada user pada area yang telah ditentukan. Hal ini disebabkan cakupan dan mobilitas pada komunikasi VLC dan IR sangat terbatas [13].

Komunikasi RF rentan terhadap interferensi elektromagnetik sedangkan VLC dan IR rentan terhadap interferensi cahaya sekitar (ambient light) [10]. Ketika membandingkan dari sisi kesehatan, RF memiliki potensi resiko yang lebih besar daripada IR dan VLC. Sedangkan IR beresiko terhadap kesehatan kulit dan mata karena pancaran radiasi tak tampak dari IR yang menimbulkan efek pemanasan yang kemudian terserap oleh dua pancaindera tersebut [14]. Perbandingan ketiga teknologi komunikasi wireless ini disajikan dalam Tabel 2.

Tabel 2. Perbandingan komunikasi RF, IR, dan

\begin{tabular}{l|ccc}
\multicolumn{4}{c}{ PLC [10] } \\
Parameter & VLC & RF & IR \\
\hline Bandwidth & $\begin{array}{c}\text { bebas } \\
\text { lisensi } \\
\text { 400 THz }\end{array}$ & $\begin{array}{c}\text { teregulasi, } \\
\text { terbatas, } \\
<300 \mathrm{GHz}\end{array}$ & $\begin{array}{c}\sim 400 \\
\mathrm{THz}\end{array}$ \\
\hline $\begin{array}{l}\text { Interferensi } \\
\text { Elektromagnetik }\end{array}$ & tidak & ya & tidak \\
\hline Konsumsi Daya & rendah & medium & rendah \\
\hline Mobilitas & terbatas & bebas & terbatas \\
\hline Standar & 802.15 .7 & $\begin{array}{c}\text { banyak, } \\
\text { matang }\end{array}$ & 802.11 \\
\hline Cakupan & sempit & luas & sempit \\
\hline $\begin{array}{l}\text { Resiko } \\
\text { Kesehatan }\end{array}$ & BLH & beberapa & panas \\
\hline Harga & rendah & $\begin{array}{l}\text { rendah- } \\
\text { medium }\end{array}$ & medium \\
\hline
\end{tabular}




\subsection{Macam-macam LED}

LED merupakan perangkat semikonduktor yang memiliki kemampuan mengubah energi listrik secara langsung menjadi energi cahaya. Sama halnya diode, struktur utama dalam LED adalah sebuah chip semikonduktor yang menciptakan $p$ - $n$ junction. Ketika dibias maju, Elektron dan hole mengalir dari junction ke elektroda dengan tegangan yang berbeda-beda. Foton terbentuk dan terpancar menjadi cahaya tampak. Efek ini disebut electroluminescence [16].

Keunggulan LED selain menghasilkan cahaya yang terang juga mampu dikontrol posisi switch on ke off atau sebaliknya dengan kecepatan tinggi sehingga memungkinkan dapat dikendalikan level iluminasinya pada frekuensi tinggi, hal ini tidak dapat dilakukan pada penerangan konvensional. Artinya LED dapat dimanfaatkan sebagai alat penerangan sekaligus komunikasi secara bersamaan. Perbandingan berbagai jenis LED yang terdapat dipasaran disajikan pada Tabel 3.

Tabel 2. Perbandingan jenis-jenis LED [10]

\begin{tabular}{|c|c|c|c|c|}
\hline Parameter & pc-LED & RGB LED & $u$ LED & OLED \\
\hline Bandwidth & 3-5 MHz & $\begin{array}{l}10-20 \\
\mathrm{MHz}\end{array}$ & $\begin{array}{l}>300 \\
\mathrm{MHz}\end{array}$ & $<1 \mathrm{MHz}$ \\
\hline $\begin{array}{l}\text { Disipasi } \\
\text { daya }\end{array}$ & $\begin{array}{c}130 \\
1 \mathrm{~m} / \mathrm{W}\end{array}$ & $65 \mathrm{~lm} / \mathrm{W}$ & N/A & $45 \mathrm{~lm} / \mathrm{w}$ \\
\hline Harga & rendah & tinggi & rendah & $\begin{array}{c}\text { Sangat } \\
\text { terjangka } \\
\mathrm{u}\end{array}$ \\
\hline $\begin{array}{l}\text { Kompleksita } \\
\mathrm{s}\end{array}$ & rendah & medium & $\begin{array}{l}\text { Sangat } \\
\text { tinggi }\end{array}$ & Tinggi \\
\hline $\begin{array}{l}\text { Aplikasi } \\
\text { spesifik }\end{array}$ & \multicolumn{2}{|c|}{ Iluminasi } & 802.11 & Display \\
\hline
\end{tabular}

Berdasarkan informasi dapat dilihat bahwa setiap jenis LED memiliki karakteristik masingmasing sehingga referensi ini dapat dijadikan pedoman untuk memilih jenis LED yang sesuai dengan kebutuhan.

\subsection{Gangguan dalam VLC}

Salah satu faktor yang sangat mempengaruhi kanal optik dari VLC ini adalah interferensi dari cahaya lain (ambient light) yang dapat berupa cahaya matahari (baik itu langsung ataupun pantulannya), lampu pijar, ataupun lampu neon.

VLC ini didesain oleh penulis ini adalah untuk aplikasi dalam ruang (indoor), sehingga sumber ambient light yang sangat berpengaruh signifikan adalah lampu pijar dan lampu neon. Photocurrent yang dibangkitkan oleh ambient light ini merupakan sumber noise pada receiver yang dapat memperburuk performa komunikasi.
Lampu pijar mengemisikan cahaya sinusoidal dengan frekunsi sekitar $100 \mathrm{~Hz}$ ketika disuplai oleh listrik dengan frekuensi $50 \mathrm{~Hz}$. Lampu neon konvensional juga membangkitkan sinyal sinusoidal terdistorsi beserta harmonisasinya pada frekuensi $50 \mathrm{~Hz}$ hingga 20 $\mathrm{kHz}$. Sementara itu lampu neon yang dinyalakan oleh ballas elektronik menghasilkan interferensi antara $50 \mathrm{~Hz}$ hingga $100 \mathrm{~Hz}$ dan $1 \mathrm{MHz}$.

\section{METODOLOGI PENELITIAN}

Untuk mencapai tujuan, penelitian ini dilaksanakan menjadi beberapa langkah, yakni:

Studi literature yakni mencari bahan materi yang berhubungan dengan teori komunikasi VLC secara Bi-directional dan teori pengenalan pola multi-warna pada LED, secara khusus LED RGB. Selanjunya melakukan review literaturliteratur penelitian yang relevan dengan penelitian yang akan dilakukan.

Penentuan spesifikasi sistem VLC yang akan dibuat, yakni: penentuan jenis konfigurasi link antara transmitter dan receiver, jarak antara transmitter dan receiver dan modulasi yang dipilih. Berdasarkan spesifikasi yang telah ditentukan, dirancanglah suatu model sistem VLC yang mendukung komunikasi bidirectional dan multiuser.

Tahap pemodelan fokus pada pemodelan dan simulasi kanal optik cahaya tampak. Pemodelan kanal optik diperlukan agar karakteristik kanal optik dapat diketahui dan dapat dijadikan referensi dalam mendesain rangkaian AFE untuk mereduksi noise.

Tahap rancangan skema penelitian lebih menitikberatkan pada sisi teknis, yakni ukuran ruang yang digunakan untuk demonstrasi rancangan, parameter-parameter yang digunakan dalam pengujian dan alat ukur yang diperlukan.

Metode perancangan dalam penelitian ini adalah pengerjaan dari level bawah ke atas (bottom up). Perancangan sistem dimulai dari dari bagian layer fisik yakni bagian DSP, secara khusus bagian modulasi selanjutnya rangkaian AFE. Untuk mendesain AFE diperlukan kegiatan simulasi untuk mengetahui apakah rangkaian yang telah dibangun melalui perhitungan matematis sesuai yang diharapkan atau tidak. Simulasi menggunakan perangkat lunak LTSpice IV. Setelah selesai simulasi selanjutnya adalah mengimplementasikan yang melibatkan perangkat keras yakni project board 
dan alat ukur berupa oscilloscope dan function generator.

Pengujian dilakukan berdasarkan skema penelitian dan selanjutnya dilakukan evaluasi, apabila tidak sesuai antara hasil dengan teori atau tidak sesuai dengan spesifikasi yang diharapkan maka dilakukan perancangan ulang dimulai dari bagian DSP. Apabila telah sesuai maka dilakukan pengemasan produk dan selanjutnya menulis laporan, terakhir adalah melakukan publikasi.

\subsection{Skema Penelitian}

Gambar 2 merupakan lingkungan dalam ruang (indoor) dengan ukuran yang telah ditentukan.

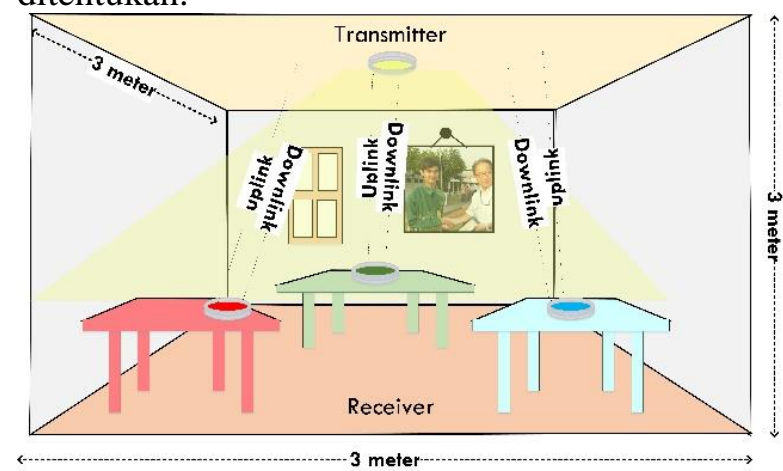

Gambar 2. Skema lingkungan sistem dalam penelitian

\subsection{Identifikasi Sistem}

VLC yang didesain terdiri dari transmitter dan receiver dengan topologi komunikasi $\mathrm{Bi}$ directional. LED digunakan sebagai antenna transmitter, penulis menggunakan LED putih dengan daya tinggi karena warna putih ini cocok digunakan sebagai sarana penerangan ruangan [26]. Daya LED yang dipilih adalah maksimum $40 \mathrm{~W}$, sehingga dapat digunakan untuk berkomunikasi setidaknya dalam jarak 1.5 hingga 3 meter dan tetap aman untuk mata manusia.

Sedangkan photodioda digunakan sebagai antenna receiver karena memiliki respon waktu yang paling cepat dibandingkan Light Dependent Resistor (LDR) dan phototransistor. Sistem mendukung komunikasi dua arah dengan multiuser yakni LED merah, LED biru dan LED hijau. Link antara antenna transmitter dan receiver ini disusun dengan konfigurasi directed LOS.

\subsection{Pemodelan}

Mengacu pada Gambar 2 tentang skema lingkungan sistem, berikut pada Gambar 3 merupakan blok diagram sistem transmitter dan sistem receiver dari penelitian ini. Topologi komunikasi antara transmitter dengan receiver adalah Bi-directional.

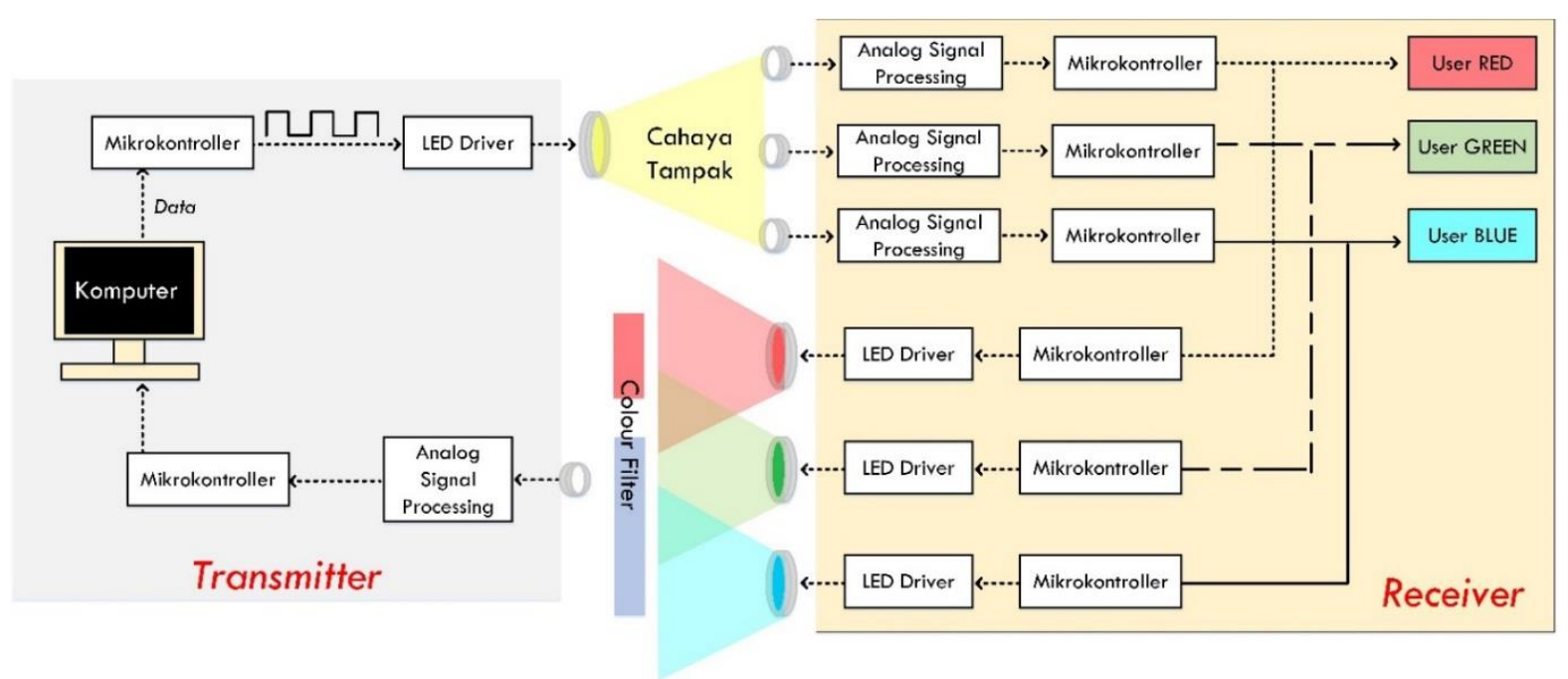

Gambar 3. Blok diagram transmitter dan receiver

Pada bagian transmitter Sistem VLC dirancang agar mampu mentransmisikan data menggunakan medium cahaya tampak. Mulamula sinyal output dari mikrokontroller dimasukkan ke rangkaian driver LED. Intensitas cahaya LED ini sesuai dengan sinyal keluaran dari modulator. Selanjutnya LED mempropagasikan sinyal termodulasi ini ke ruang bebas menggunakan medium cahaya tampak. Dengan menggunakan metode Direct Detection, intensitas cahaya yang dipancarkan oleh LED diterima oleh photodioda dan diubah 
menjadi sinyal listrik yang linier terhadap intensitas cahaya yang diterima. Sinyal yang diterima tersebut rentan terhadap noise dan interferensi yang mungkin terjadi selama sinyal merambat di ruang bebas. Rangkaian analog signal processing berfungsi untuk mengkondisikan sinyal terdistorsi sehingga dapat diolah dengan baik oleh demodulator yang pada akhirnya data dapat diubah kembali sesuai dengan data asli.

Pada bagian receiver, user dapat melakukan uplink data ke transmitter. Terdapat tiga user dalam skema penelitian ini yang direpresentasikan ole LED merah, LED hijau dan LED biru. Ketiga LED ini difungsikan sebagai multiuser. Sistem dapat mengenali pola warna sehingga dapat mengetahui user mana yang sedang meminta akses.

\subsection{Pemodelan Modulasi}

Dalam penelitian ini, modulasi dijital yang dipilih adalah Pulse Width Modulation (PWM). Implementasi modulasi dijital cenderung lebih sederhana dibanding modulasi lainnya baik itu untuk implementasi AFE maupun DSP, karena pada modulasi ini hanya memerlukan dua kondisi yaitu lampu menyala dan padam. PWM memodulasi data terhadap lebar pulsa. Jenis modulasi ini dipilih karena dapat mendukung modulasi multi-level. Dengan modulasi multilevel, maka pulsa untuk tiap satu periode mampu membawa bit lebih banyak.

Pulse Width Modulation (PWM) mengkodekan pesan terhadap lebar pulsa atau duty cycle. Istilah duty cycle menunjukkan perbandingan antara waktu 'on' terhadap periode satu pulsa. Dalam sistem komunikasi, duty cycle pada PWM digunakan untuk membawa informasi melewati kanal komunikasi.

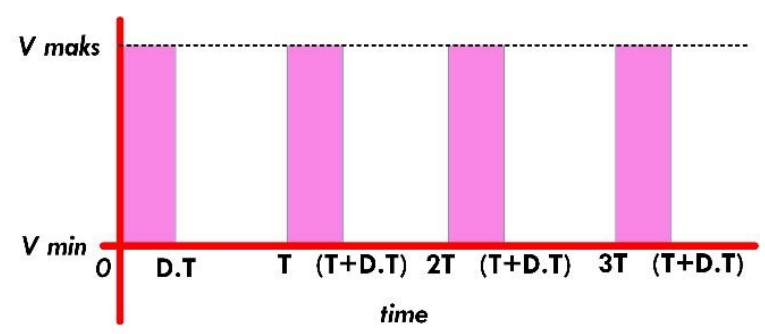

Gambar 3. Bentuk gelombang pulsa PWM

Nilai rata-rata dari gelombang tersebut adalah,

$\bar{v}$

$=\frac{1}{T} \int_{0}^{T} v(t) d t$
Karena $v(t)$ adalah memiliki nilai maksimum $v_{\text {maks }}$ pada saat $0<\mathrm{t}<\mathrm{D}$.T dan nilai minimum $\mathrm{V}_{\min }$ pada saat D.T $<\mathrm{t}<\mathrm{T}$, maka persamaan 1 menjadi:

$\bar{v}=\frac{1}{T}\left(\int_{0}^{D T} v_{\max } d t+\int_{D T}^{T} v_{\min } d t\right)$

$\bar{v}$

$=\frac{D \cdot T \cdot v_{\max }+T(1-D) v_{\min }}{T}$

$\bar{v}=D \cdot v_{\max }+(1-D) v_{\min }$

VLC yang dirancang ini menggunakan mekanisme Intensity Modulation (IM) dan Direct Detection, maka tegangan $v$ adalah tegangan LED $\left(\mathrm{V}_{\mathrm{LED}}\right)$. Sehingga daya pada LED adalah,

$P_{L E D a}=v_{L E D} i_{L E D}$

Dimana $i$ adalah arus. Intensitas (I) dari LED akan sangat dipengaruhi dari daya LED,

$I_{L E D} \approx P_{L E D}$

Tegangan output modulasi $v$ tersebut sangat mempengaruhi intensitas LED. Semakin tinggi nilai $v$, maka semakin tinggi intensitas LED/semakin terang dan begitu juga sebaliknya. Berdasarkan persamaan 4, nilai $v$ sangat bergantung terhadap D (duty cycle). Apabila PWM digunakan untuk memodulasi data dijital 1 bit, maka untuk membedakan data 0 dan 1 adalah dengan memvariasikan nilai D. Apabila PWM digunakan dalam VLC, maka nilai D harus dipilih cukup lebar sehingga noise marginnya tinggi namun harus cukup sempit sehingga tidak menimbulkan efek dimming terhadap fungsi pencahayaan.

\subsection{Analog Front End (AFE)}

Jenis LED driver yang dirancang dalam penelitian ini yaitu LED driver yang mendukung modulasi PWM dijital. Sedangkan pada rangkaian Analog pada receiver berfungsi untuk mengkondisikan sinyal yang diterima oleh photodioda. Blok diagram dari analog receiver ditunjukkan pada Gambar 4. 


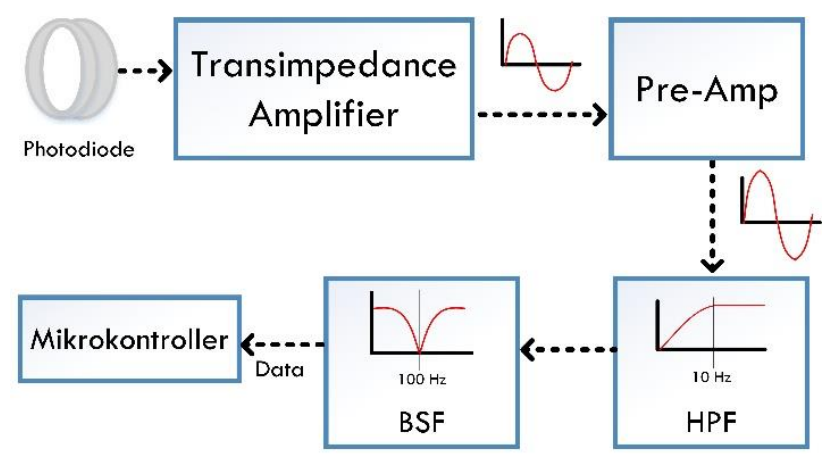

Gambar 4. Rangkaian AFE Receiver

Sinyal yang dibangkitkan oleh photodioda diinputkan pada transimpedance amplifier (TIA) yang berfungsi mengubah arus menjadi tegangan. Pre-amplifier adalah penguat tegangan tahap pertama karena amplitudo sinyal keluaran dari TIA masih terlalu kecil. High pass filter digunakan untuk menghilangkan tegangan DC offset secara otomatis. Band stop filter atau notch filter didesain untuk menghilangkan interferensi sinyal dengan frekuensi $100 \mathrm{~Hz}$ yang dibangkitkan oleh sumber cahaya lain seperti lampu neon.

\section{PENUTUP}

Media komunikasi merupakan sebuah platform untuk meningkatkan kualitas kehidupan yang lebih baik dan menjadi pendorong kegiatan ekonomi. Dengan memanfaatkan infrastruktur sistem penerangan yang sudah banyak tersedia di berbagai tempat, maka VLC berpotensi besar digunakan sebagai alternatif komunikasi nirkabel di masa depan.

Hasil penilitian ini nantinya dapat memberikan sumbangan pengetahuan tentang bagaimana platform VLC yang Bi-directional sekaligus multiuser dimana user-user tersebut direpresentasikan oleh LED merah, hijau dan biru dan sistem dapat mengenalinya saat user melakukan uplink. Platform didesain dengan kecepatan Donwlink adalah 1 Mbps sehingga dalam aplikasinya cukup digunakan untuk memutar video kualitas 3GP.

Harapan dari penulis adalah hasil produk/sistem dari penelitian ini dapat diterapkan sebagai platform komunikasi yang ideal untuk diterapkan pada skala dalam ruang baik perkantoran ataupun rumah hunian dimasa mendatang. Lebih jauh lagi, dapat dijadikan referensi dan tolok ukur dalam pengembangan penelitian-penelitian yang lebih lanjut baik dari penulis sendiri ataupun peneliti mancanegara sehingga pada akhirnya menjadi standar platform IEEE 802.15.7 untuk skema Bidirectional sekaligus Multiuser pada sisi physical layer.

\section{DAFTAR PUSTAKA}

[1] Z. Ghassemlooy, W. Popoola, and S. Rajbhandari, Optical Wireless Communications: System and Channel Modelling With MATLAB. Boca Raton, FL, USA: CRC Press, 2012.

[2] "Infrared data association," Walnut Creek, CA, USA, 2012. [Online]. Available: http://www.irda.org

[3] Tsonev D., Chun H., Rajbhandari S., McKendry J., Videv S., Gu E., Haji M., Watson S., Kelly A., Faulkner G., Dawson M., Haas H. and O'Brien D., A 3Gb/s single-LED OFDM-based wireless VLC link using a gallium nitride $\mu \mathrm{LED}$, IEEE Photonics Technology Letters Volume 26 Issue 7, pp. 637 - 640, 2014

[4] A. Ramadhan, L. Lidyawati2, D. Nataliana, "Implementasi Visible Light Communication (VLC) Pada Sistem Komunikasi," J. Elkomika, Vol. 1(1), pp. 13-25, 2013.

[5] K. Bandara, Y.H.Chung, Novel Colorclustered Multiuser Visible Light Communication, Trans. Emerg. T elecommucation Technol., 25(6), pp. 579-590, 2014.

[6] J.M.L. Rivera, R.P. Jimenez, J.A.R. Borjes, J.F.R. Torres, V.Guerra, C.S. Rodriguez, Multiuser CSK scheme for indoor visible light communications, Opt. Express, 22(20), pp. 24256-24267, 2014.

[7] A.Sewaiwar, S.V. Tiwari, Y.H. Chung, Novel user allocation scheme for full duplex multiuser bidirectional, $\mathrm{Li}-\mathrm{Fi}$ network, Opt.Commun. 339, pp. 153-156. 2014

[8] C. Tang, M. Jiang, H. Shen, C. Zhao, "Analysis and Optimization of P-LDPC Coded RGB-LED-Based VLC Systems," IEEE Photonics J. Vol. 7 (6), December 2015

[9] H. Parikh, J. Chokshi, N. Gala, and T. Biradar, "Wirelessly transmitting a grayscale image using visible light," in Proc. ICATE, pp. 1-6, 2013.

[10] D. Karunatilaka, F. Zafar, V. Kalavally, "LED Based Indoor Visible Light Communications: State of the Art," IEEE 
Communication Surveys \& Tutorials, Vol. 17(3), pp. 1649-1678, 2015.

[11] Q. Wang, Z. Wang, L. Dai, "Multiuser MIMO-OFDM for Visible Light Communications," IEEE Photonics J. Vol. 7 (6), December 2015

[12] S. Zhao, J. Xu, and O. Trescases, "A dimmable LED driver for Visible Light Communication (VLC) based on LLC resonant DC-DC converter operating in burst mode," in Proc. 28th Annu. IEEE APEC Expo, pp. 2144-2150, 2013.

[13] Y. Wang, Y. Wang, N. Chi, J. Yu, and H. Shang, "Demonstration of $575-\mathrm{mb} / \mathrm{s}$ downlink and $225-\mathrm{mb} / \mathrm{s}$ uplink bidirectional SCM-WDM visible light communication using RGB LED and phosphor-based LED," Opt. Exp., vol. 21(1), pp. 1203-1208, January 2013.

[14] E. Schubert, Light-Emitting Diodes. Cambridge, U.K.: Cambridge Univ. Press, 2006.

[15] S. Wu, H. Wang, and C-H. Young, "Visible Light Communications for 5G Wireless Networking Systems: From Fixed to Mobile Communications," IEEE Network, Vol. 29(6), pp. 41-45, November 2014.

[16] Y.Gu, N. Narendran, T. Dong, and H. Wu, "Spectral and luminous efficacy change of high-power LEDs under different dimming methods," in Proc. 6th Int. Conf. Solid State Lighting, Vol. 6337, 2006, Art. ID. 63370J

[17] S.V. Tiwari, A. Sewaiwar, Y.H. Chung, "Color coded multiple access scheme for bidirectional multiuser visible light communications in smart home technologies", ELSEVIER Optics Communications, Vol.353, pp. 1-5, October 2015.

[18] S.H. Yang, H.S. Kim, Y.H. Son, S.K. Han, "Reduction of Optical Interference by Wavelength Filtering in RGB-LED Based Indoor VLC System", The $16^{\text {th }}$ Opto-Electronics and Communications Conf. (OECC), pp. 551-552, Juli 2011.
[19] B. Li, J. Wang, R. Zhang, H. Shen, C. Zhao, L. Hanzo, Multiuser MISO Transceiver Design for Indoor Downlink Visible Light Communication Under PerLED Optical Power Constraints", IEEE Photonics Journal Vol.7(4), \#Article 7201415, Agust 2015.

[20] H. Ma, L. Lampe, S. Hranilovic, "Coordinated Broadcasting for Multiuser Indoor Visible Light Communication Systems", IEEE Transactions on Communications, Vol. 63(9), pp. 33133324, July 2015.

[21] S.H. Chen, C.W. Chow, "Color-FilterFree Wdm Mimo Rgb-Led Visible Light Communication System Using MobilePhone Camera", IEEE 2014.

[22] G. Cossu, A.M. Khalid, P. Choudhury, R. Corsini, E. Ciaramella, Long Distance Indoor High Speed Visible Light Communication System Based on RGB LEDs, Communications and Photonics Conf. (ACP), pp.1-3, November 2012.

[23] W. Yuanquan and C. Nan, "A High-Speed Bi-Directional Visible Light Communication System Based on RGBLED”, China Communications Vol.11 (3), pp.40-44, March 2014.

[24] J.M.L. Rivera, R.P. Jimenez, J.A.R. Borjes, J.F.R. Torres, V.Guerra, C.S. Rodriguez, "Multiuser Scheme for Indoor Visible Light Communications using RGB LEDs", Int. Work Conf. on Bio-Inspired Intellegenge (IWOBI), pp. 119-123, July 2014.

[25] A. Sewaiwar, P.P. Han, Y. H. Chung, "3Gbit/s Indoor Visible Light Communications Using Optical Diversity Schemes," IEEE Photonics J. Vol. 7 (6), December 2015

[26] Y. Wang, Y. Shao, H. Shang, X. Lu, Y. Wang, J. Yu, N. Chi, "875-Mb/s Asynchronous Bi-directional 64QAMOFDM SCM-WDM Transmission over RGB-LED-based Visible Light Communication System," Optical Fiber Communication Conference (OFC) 2013 paper: OTh1G.3. 